\title{
CONVERSAS COM PÓS-GRADUANDOS
}

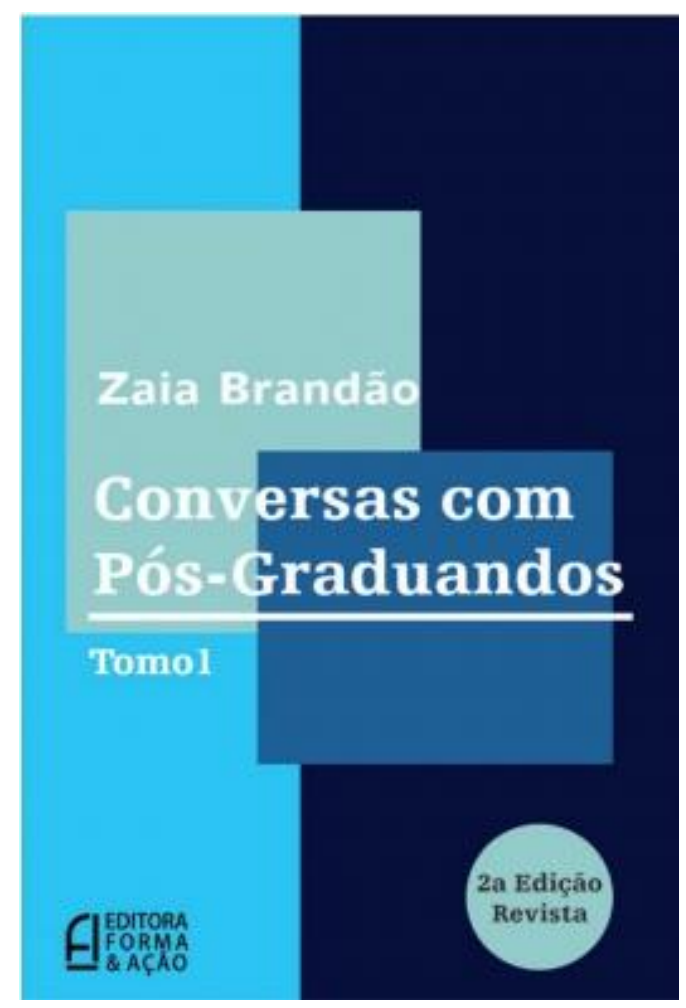

BRANDÃO, Zaia. Conversas com pósgraduandos. Rio de Janeiro: Forma e Ação, 2010. 124 p.

Resenhado por:

Mariana Silva Santos

Universidade Federal de Ouro Preto

Conversas com pós-graduandos, de autoria Zaia Brandão, é composto por cinco capítulos, que correspondem a cinco ensaios, em que a autora aborda temáticas relativas ao ofício do pesquisador, baseada em sua experiência como pesquisadora e orientadora de discentes. No decorrer da obra, a autora trata de questões referentes ao ofício do pesquisador, sobretudo o pesquisador iniciante. A procura pela bibliografia, a metodologia e a prática interdisciplinar na pesquisa em educação são alguns tópicos discutidos por Brandão.

Olh@res, Guarulhos, v. 1, n1, p. x-xx, dez./jan. 2012. 
No primeiro capítulo, Conversas com pós-graduandos (sobre leituras, trabalhos acadêmicos e pesquisa em educação), a autora discute alguns problemas enfrentados pelos estudantes de pós-graduação, aqueles que, normalmente, são considerados pesquisadores iniciantes. Uma boa pósgraduação, afirma Brandão, não pode prescindir de uma familiarização intensa com a literatura da área (BRANDÃO, 2010, p.15). Essa intimidade será adquirida por meio da construção do habitus científico, que significa conhecer as obras importantes da área por meio de uma imersão na biblioteca, de um exercício de curiosidade e pesquisa (BRANDÃO, 2010, p.17). A noção de habitus empregada pela autora advém de Bourdieu, e pode ser traduzida pelas experiências vivenciadas pelo sujeito, experiências essas que estruturam internamente sua subjetividade, constituindo uma matriz de percepções e apreciações que orientaria as ações do sujeito nas situações subsequentes (NOGUEIRA, 2006, p.28). Esse habitus acabará por desenvolver no pesquisador um faro intelectual (BRANDÃO, 2010, p.22). O conhecimento dos autores, no entanto, não deve ser transformado num processo sem fim de citações no trabalho acadêmico. Essas não devem ser utilizadas apenas para aumentar ou adensar o texto, mas para recorrer a um argumento de autoridade, referir-se originalmente a algum assunto, exemplificar, ou ainda colocar uma epígrafe (BRANDÃO, 2010, p.20).

O segundo capítulo, Entre questionários e entrevistas, tem como foco os cuidados necessários à utilização de entrevistas e questionários. Para atender a essa proposta, ela inicia a discussão criticando os antagonismos micro/macrossocial, qualitativo/quantitativo, no que se refere à análise de fenômenos sociais. Esses seriam, segundo Brandão, complexos demais para serem analisados a partir de uma ortodoxia metodológica. O monismo metodológico e a aceleração inadequada, explicados a seguir, são atitudes equívocas para a prática da pesquisa. A autora utiliza Bourdieu para afirmar que o monismo metodológico é resultado da arrogância da ignorância, e que o pesquisador opta pelo método quantitativo ou qualitativo pela incapacidade de trabalhar com o outro (BRANDÃO, 2010, p.32).

Olh@res, Guarulhos, v. 1, n1, p. 505-510, maio. 2013. 
A autora chama a atenção para a aceleração inadequada em dois momentos cruciais da pesquisa: o da delimitação do objeto e o da análise e interpretação dos resultados. Adquirir rigor científico também pode se configurar numa dificuldade, uma vez que tal atividade exige tempo e esforço, e a consciência de que os materiais de pesquisa não são dados, mas construídos (BRANDÃO, 2010, p.33-35). O trabalho de pesquisa não pode prescindir de uma teoria colocada a priori, mas ela pode e deve ser testada pelo trabalho de campo (BRANDÃO, 2010, p.38). A fim de dizer qual instrumento é mais adequado em cada caso, Brandão estabelece uma diferença entre entrevistas e questionários a partir de Blanchet \& Gotman (1992). Questionários seriam utilizados quando o pesquisador conhece o mundo de referência, enquanto entrevistas são mais úteis quando se ignora o mundo de referência (BRANDÃO, 2010, p.45). Ambos, questionários e entrevistas, precisam ancorar-se em categorias que, quando bem definidas, asseguram a consistência dos dados produzidos, possibilitando análises e interpretações mais densas (BRANDÃO, 2010, p.47).

O terceiro capítulo, A construção de um objeto de pesquisa (problematizando a interdisciplinaridade), trata sobre a temática da interdisciplinaridade. Mesmo acreditando na importância da prática, a autora chama a atenção para o cuidado que se deve ter ao empregá-la. A importância da prática seria, portanto, assegurada pela flexibilização das fronteiras entre as áreas do conhecimento, o que exige que os pesquisadores se atentem ao que tem sido produzido acerca de seus objetos por outras áreas ou campos do conhecimento. Alerta, ainda, que apenas utilizar o vocabulário e algumas referências de uma área específica não determina uma prática interdisciplinar consistente, mas práticas de pesquisa pouco rigorosas (BRANDÃO, 2010, p.58/59). A autora discute alguns autores que se posicionam acerca da interdisciplinaridade, a saber: Luiz Eduardo Soares (1991), que afirma ser necessário que a interdisciplinaridade se ancore em um campo disciplinar (BRANDÃO, 2010, p.60); Bourdieu (1990), para o qual a interdisciplinaridade requer uma cultura teórica que garantirá opções teórico-metodológicas adequadas aos problemas de pesquisa (BRANDÃO, Olh@res, Guarulhos, v. 1, n1, p. 505-510, maio. 2013. 
2010, p.61); e Viviane Isambert-Jamati (1992), que defenderá a interdisciplinaridade na pesquisa em educação (BRANDÃO, 2010, p.61). Brandão discute acerca de dois entraves existentes no que se refere à interdisciplinaridade. O primeiro refere-se ao risco de unir disciplinas que não tenham congruência para explicar fenômenos educacionais e, o segundo, aos limites impostos pela especialização disciplinar para esse mesmo fim (BRANDÃO, 2010, p.62). Para ilustrar essa questão, a autora expõe uma experiência de pesquisa em que ela relacionou História e Educação para problematizar a responsabilidade atribuída aos Pioneiros da Educação Nova pela construção de um sistema público de ensino no Brasil. $\mathrm{Na}$ leitura e na utilização das fontes de sua pesquisa, e a partir de movimentos de questionamento e problematização das ideias de Paschoal Lemme - que era partidário de uma visão de esquerda e propunha uma modernização da escolarização - a autora aprimora sua maneira de pesquisar, buscando na própria História outras perspectivas (como a historiografia que relaciona História e Memória) e produzindo um resultado mais satisfatório. Esse processo é denominado por ela de mergulho disciplinar (BRANDÃO, 2010, p.70), que no caso específico dessa experiência relatada deu-se pelo aprofundamento na leitura de historiadores de ofício a fim de melhorar a reflexão sobre problemas teóricos do campo da educação (BRANDÃO, 2010, p.72). A conclusão desse ensaio é feita com uma questão acerca da capacidade dos programas de pós-graduação em fornecer cultura teórica aos seus estudantes (BRANDÃO, 2010, p.75).

No capítulo quatro, A teoria como hipótese, Brandão aborda duas características do campo científico atual: a flexibilização das fronteiras entre as áreas do conhecimento e a flexibilização da noção de verdade científica (BRANDÃO, 2010, p.84). Segundo a autora, há uma recorrente afirmação de que a pesquisa educacional tem se revestido de pouca consistência e de uma ausência de tradição teórica. Tende-se a reproduzir teorias em vez de operar criticamente com as referências teóricas (BRANDÃO, 2010, p.86). Em decorrência dessa parca consistência teórica e reafirmando a necessidade da prática interdisciplinar, Brandão afirma que a pesquisa em

Olh@res, Guarulhos, v. 1, n1, p. 505-510, maio. 2013. 
educação depende de outras áreas (BRANDÃO, 2010, p.87). A autora desenvolve uma reflexão sobre o processo de constituição da pesquisa em educação como campo especializado, a partir de três momentos: a procura do estatuto científico; a procura da identidade científica; a procura de uma hegemonia teórica (BRANDÃO, 2010, p.87). No que se refere à procura do estatuto científico, afirma que o principal objetivo é a experimentação, representada pelas ações de explorar e provar. O estatuto científico acredita na neutralidade, na separação entre o sujeito que investiga e o objeto de investigação. (BRANDÃO, 2010, p.88). Quando trata da procura da identidade científica, um dos pressupostos é o de que se deve explicitar o lugar de onde se fala, ou seja, não se parte para a empiria sem uma teoria (BRANDÃO, 2010, p.90). Quando se detém na explicação do último momento, o da procura da hegemonia teórica, destaca a crescente importância da fala hegemônica dentro de uma comunidade especializada, que constitui um público consumidor de uma fala comum (BRANDÃO, 2010, p.91). A hegemonia teórica instaura uma disputa teórica a fim de definir qual o melhor parâmetro teórico-metodológico para um campo, o que faz com que a teoria assuma um tom de verdade (BRANDÃO, 2010, p.92). Brandão refuta a noção de teoria como explicação do real, afirmando que, para ela, a teoria é sempre uma hipótese (BRANDÃO, 2010, p.95). Afirma ainda que, quanto mais atingimos o conhecimento, mais temos noção da nossa ignorância (BRANDÃO, 2010, p.96).

O quinto e último capítulo, Para além das ortodoxias (a dialética micro/macro na sociologia da educação), aborda uma questão já tangenciada anteriormente no livro em questão, da necessidade de superação do antagonismo entre as perspectivas micro e macrossociológicas na sociologia da educação (BRANDÃO, 2010, p.102). Há um movimento denominado novas sociologias ou novo movimento teórico que exclui essa dicotomia entre micro e macrossocial, afirmando que o coletivo é individual e que o micro forma o macro (BRANDÃO, 2010, p.106).

Existem, segundo Brandão, duas posições epistemológicas polares sobre as perspectivas micro/macro. A primeira pretende construir teorias gerais sobre Olh@res, Guarulhos, v. 1, n1, p. 505-510, maio. 2013. 
as relações sociais, centralizando-se nas estruturas da sociedade (BRANDÃO, 2010, p.106). A segunda descarta noções gerais para definir a sociedade, adotando para análise fragmentos microssociais (BRANDÃO, 2010, p.107). A autora cita o sociólogo americano Jeffrey C. Alexander para abordar o novo movimento teórico. No contexto do pós-Segunda Guerra surgem, segundo ele, perspectivas microssociais de inspiração fenomenológica, como a teoria das trocas, o interacionismo simbólico e a etnometodologia (BRANDÃO, 2010, p.108). Surgem, por outro lado, perspectivas macrossociais, defendidas pelos "teóricos do conflito" (BRANDÃO, 2010, p.109). O que Alexander afirma é que o novo movimento teórico intenta juntar essas duas perspectivas objetivando uma melhor compreensão da relação entre o individual e o coletivo, a partir do estudo da cultura. Essa perspectiva do novo movimento teórico, no entanto, não encontrou adeptos entre nós (BRANDÃO, 2010, p.116). Brandão reconhece a necessidade de se articular as duas perspectivas, negando a superioridade de uma ou de outra, mas transfere ao pesquisador a responsabilidade para optar pelo instrumento de análise mais adequado para investigar seu problema, considerando o seu campo de pesquisa (BRANDÃO, 2010, p.121).

\section{Referências Bibliográficas}

NOGUEIRA, Maria Alice; NOGUEIRA, Cláudio M. Martins. Bourdieu \& a Educação. Belo Horizonte: Autêntica, 2006.

Olh@ res, Guarulhos, v. 1, n1, p. 505-510, maio. 2013. 